\title{
O efeito da pandemia na estratégia nacional para o turismo em Portugal: $O$ desafio da sustentabilidade
}

\section{The effect of the pandemic on the national strategy for tourism in Portugal: The challenge of sustainability}

\author{
Sandra Bailoa \\ Instituto Politécnico de Beja, Portugal \\ sandra.bailoa@ipbeja.pt \\ http://orcid.org/0000-0001-8411-5080 \\ Pedro Cravo \\ Instituto Politécnico de Beja, Portugal \\ pedro.cravo@ipbeja.pt \\ https://orcid.org/0000-0002-4209-1962
}

\begin{abstract}
Resumo
Em Portugal, sobretudo a partir da última década, as estratégias nacionais para o turismo têm refletido preocupação com o desenvolvimento sustentável da atividade. Esta preocupação tornou-se o desígnio da atual Estratégia Turismo 2027 e acentuou-se com o contexto da pandemia Covid-19, a qual trouxe grandes dificuldades ao setor do turismo. A recuperação do setor está a ser encarada como uma oportunidade de planear as atividades com base nos princípios da sustentabilidade. Assim, este artigo pretende analisar a presença da sustentabilidade enquanto filosofia de desenvolvimento na evolução das estratégias nacionais para o turismo e analisar o efeito da pandemia na atual estratégia. A análise permitiu perceber que o principal efeito da pandemia na estratégia nacional foi levar ao aceleramento na implementação de práticas sustentáveis. A publicação do Plano Turismo +Sustentável 20-23 mostra ser a primeira fase do desafio de tornar Portugal um destino turístico sustentável.
\end{abstract}

Palavras-chave: Covid-19; estratégia nacional; Portugal; sustentabilidade; turismo.

\begin{abstract}
In Portugal, especially since the past decade, the national strategies for tourism have reflected concern with the development of the activity based on sustainability principles. This concern has become the goal of the current Tourism Strategy 2027 and has been enhanced by the context of the Covid-19 pandemic, which brought great difficulties to the tourism sector. The sector's recovery is being seen as an opportunity to plan activities based on the principles of sustainable development. Thus, this article intends to analyse the presence of sustainability as a development philosophy in national tourism strategies and to analyse the effect of the pandemic on the current strategy. The analysis showed that the main effect of the pandemic on the national strategy was to accelerate the implementation of sustainable practices. The publication of the Tourism Plan +Sustainability 20-23 shows that it is the first phase of the challenge of making Portugal a sustainable tourist destination.
\end{abstract}

Keywords: Covid-19; national strategy; Portugal, sustainability; tourism.

Dos Algarves: A Multidisciplinary e-Journal, 40-2021.

ISBN 2182-5580 @ ESGHT - University of the Algarve, Portugal.

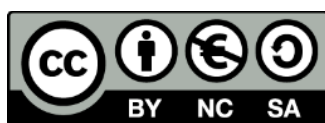

To cite this article: Bailoa, S. \& Cravo, P. (2021). O efeito da pandemia na estratégia nacional para o turismo em Portugal: $O$ desafio da sustentabilidade. Dos Algarves: A Multidisciplinary e-Journal, 40, 31-47. DOI: 10.18089/DAMeJ.2021.40.2 


\section{Introdução}

A sustentabilidade da atividade turística revelou-se numa crescente preocupação, sobretudo a partir das últimas décadas do século $\mathrm{XX}$, com o crescimento acentuado do turismo. Em Portugal, o turismo é considerado um setor estratégico de desenvolvimento económico, sendo possível encontrar algumas estratégias nacionais para o desenvolvimento do setor. Nesse sentido, importa perceber se as estratégias de desenvolvimento do turismo em Portugal têm refletido preocupação com a sustentabilidade.

Atualmente o contexto da pandemia Covid-19 veio trazer grandes dificuldades às empresas e outras entidades do setor do turismo devido à paragem das atividades. Sendo o turismo um dos setores mais afetados torna-se necessário refletir sobre como enfrentar os desafios da pandemia. A recuperação do setor está a ser vista como uma oportunidade de repensar o desenvolvimento das atividades de acordo com os princípios do desenvolvimento sustentável (Gössling et al., 2021; Palacios-Florencio et al., 2021, Sharpley, 2021; Butcher, 2021). Então, importa igualmente perceber se a pandemia provocou alterações na estratégia nacional para o turismo.

Desta forma, este trabalho teve como objetivos: analisar a presença da sustentabilidade enquanto filosofia de desenvolvimento na evolução das estratégias nacionais para o turismo em Portugal; e analisar o efeito da pandemia na atual estratégia. A metodologia utilizada passou, essencialmente, pela pesquisa bibliográfica, pela análise documental dos planos nacionais do turismo focada nas referências à sustentabilidade e ainda pela consulta e análise de estatísticas disponíveis online.

O artigo encontra-se dividido em três secções principais. Na primeira secção é abordada a origem do conceito de desenvolvimento sustentável e analisada a sustentabilidade do turismo no contexto da pandemia Covid-19. Na segunda secção é analisada a presença do desígnio da sustentabilidade nas sucessivas estratégias nacionais para o Turismo em Portugal. Na terceira secção é analisado o principal efeito da pandemia na estratégia nacional para o turismo nomeadamente a publicação do Plano Turismo +Sustentável 20-23. Por último, são apresentadas as principais conclusões.

\section{A sustentabilidade do turismo e a pandemia Covid-19}

O crescimento acentuado dos movimentos turísticos trouxe preocupações com o desenvolvimento sustentável do turismo. Diversas investigações ao longo das três últimas décadas têm apontado para a necessidade do turismo se desenvolver de acordo com os fundamentos da sustentabilidade, tendo o turismo sustentável subsistido enquanto paradigma dominante de desenvolvimento da atividade entre académicos e políticos (Sharpley, 2021).

O conceito de desenvolvimento sustentável está intimamente relacionado com a preocupação gerada pelos impactes que a intervenção do Homem tem na Natureza. Considera-se, habitualmente, que o conceito de "desenvolvimento sustentável” teve origem no Relatório Brundtland - Our Common Future (United Nations, 1987), apresentado à Assembleia Geral das Nações Unidas em agosto de 1987. Segundo este, o desenvolvimento sustentável é aquele que: 
Satisfaz as necessidades do presente sem comprometer a possibilidade de as gerações futuras satisfazerem as suas próprias necessidades. O conceito de desenvolvimento sustentável implica limites - não limites absolutos, mas limitações impostas pelo estado atual da tecnologia e organização social sobre os recursos ambientais e pela capacidade que a biosfera tem de absorver os efeitos das atividades humanas. (UN, 1987: 24)

De acordo com Holden (2008) o termo foi popularizado a partir do seu uso no referido Relatório Brundtland. Para isso contribuiu também a 'Earth Summit' realizada no Rio de Janeiro em junho de 1992 na qual foi adotada a Agenda 21, que se constituiu um documento orientador dos governos, das organizações internacionais e da sociedade civil, para o desenvolvimento sustentável (United Nations, 1992). A partir deste evento, vários outros relacionados com o desenvolvimento sustentável se foram sucedendo, como a Conferência de Quioto (1997), e as Cimeiras do Milénio (2000), Rio+10 (2002) e Rio+20 (2012), que vieram a culminar na Cimeira das Nações Unidas para o Desenvolvimento Sustentável de 2015, onde foi votada a Agenda 2030 para o Desenvolvimento Sustentável (United Nations, 2020). Entre estas iniciativas destaca-se a mais atual, a Agenda 2030 para o Desenvolvimento Sustentável, a qual contém 17 Objetivos de Desenvolvimento Sustentável (ODS) e 169 metas e foi assinada pelos chefes de estado e de governo dos 193 Estados-Membros da ONU entrando em vigor em janeiro de 2016. Esta prevê um prazo de 15 anos para que sejam alcançados os ODS previstos. Na Figura 1 são apresentados os 17 ODS. Destacamos a necessidade de erradicar a pobreza, o objetivo número um, mas que abarca um vasto leque de tópicos interrelacionados, tanto a nível da dimensão económica (presente no objetivo número oito, por exemplo), como social (objetivos dois, três, quatro e cinco, entre outros) e ambiental (objetivos sete, catorze e quinze, por exemplo).

Figura 1 - Objetivos do Desenvolvimento Sustentável (ODS) da UN

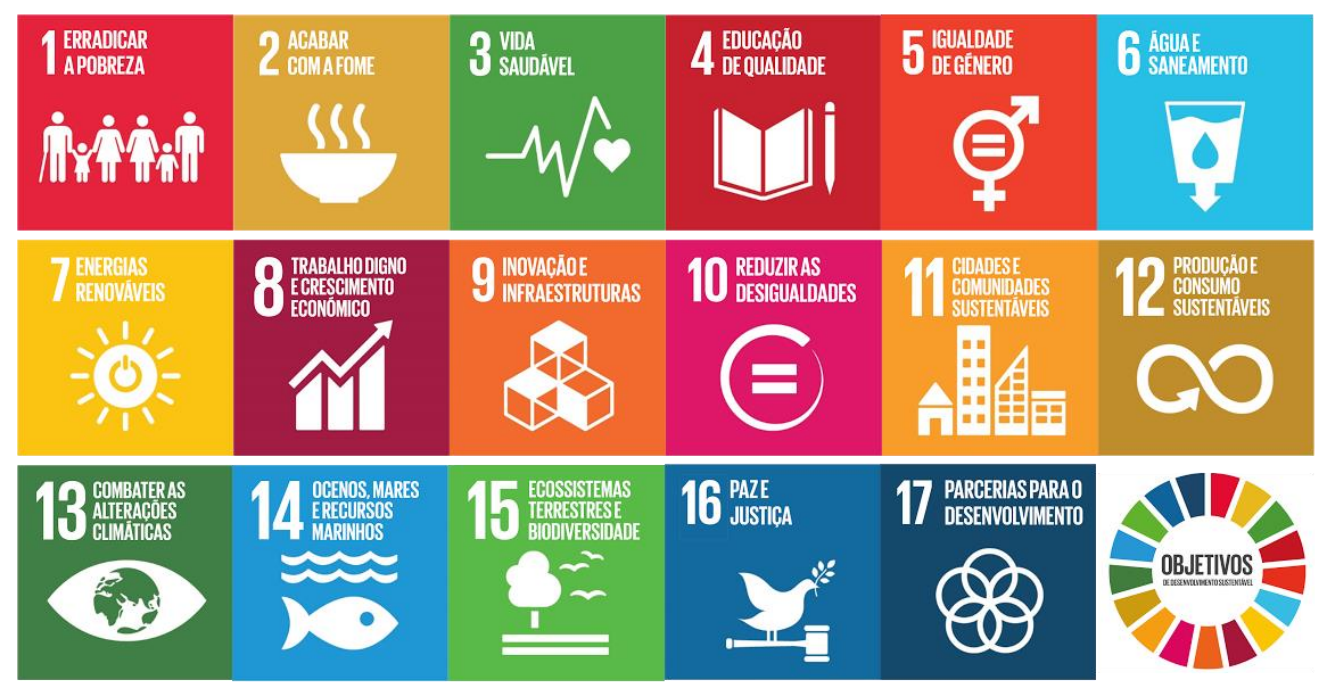

Fonte: https://www.dge.mec.pt/objetivos-de-desenvolvimento-sustentavel-ods

De acordo com Holden (2008) é em 1997 na 'Earth Summit II' (Nova lorque) que o turismo é reconhecido como um setor económico que precisa de se desenvolver de forma sustentável. De facto, a sustentabilidade da atividade turística revelou-se uma questão central devido ao crescimento acentuado do turismo no final do seculo XX. Neste setor os 
impactes negativos e baixos níveis de satisfação dos turistas resultantes da falta de planeamento e excessos de exploração económica destas atividades, juntamente com a tentativa de compatibilização da maximização dos rendimentos desta atividade com a minimização dos efeitos negativos do turismo de massa, permitiram o crescimento da discussão sobre o desenvolvimento sustentável do turismo.

Analisando o conceito de desenvolvimento sustentável na área do turismo podemos encontrar as expressões "turismo sustentável" e "desenvolvimento turístico sustentável". De acordo com Holden (2008) o termo desenvolvimento sustentável é ambíguo e pode ser alvo de diferentes interpretações mesmo quando aplicado ao turismo. Refere que a diferença reside entre aqueles que interpretam "turismo sustentável" como defendendo a sustentação do turismo num destino, e aqueles que defendem o turismo como um veículo para alcançar o desenvolvimento sustentável, que abrange objetivos e prioridades socialmente determinados muito mais amplos (Holden, 2008). Não pretendendo aprofundar esta discussão, este trabalho seguirá a noção de sustentabilidade evidenciada pela UNEP/WTO (2005).

Segundo a UNEP/WTO (2005), os princípios da sustentabilidade referem-se aos aspetos ambientais, económicos e socioculturais de desenvolvimento do turismo, devendo ser estabelecido um equilíbrio adequado entre estas três dimensões para garantir a sua sustentabilidade a longo prazo, podendo estes aspetos ser aplicáveis a todas as formas de turismo em todos os tipos de destinos. Neste sentido diversos autores encaram a sustentabilidade da atividade baseada na compatibilização dessas três dimensões. Para Almeida e Abranja (2009) a não sustentabilidade do turismo resulta da colisão, devido à sua incompatibilidade, entre o turismo, o ambiente, a economia e a sociedade, gerando impactes negativos como: poluição da água e do ar; poluição sonora; congestionamento de veículos e grandes aglomerados de pessoas; poluição visual com o incorreto uso da terra e mau planeamento do local; danificação dos recursos; e desequilíbrio ecológico das áreas naturais. Holden (2008) refere que o turismo sustentável não está apenas relacionado com a conservação ou preservação do meio ambiente físico, mas incorpora dimensões culturais, económicas e políticas. Para Santos (2014) uma interpretação sustentável do turismo deve ter em conta a sustentabilidade territorial, que se estrutura nos seguintes vértices principais: as valências económicas (importantes para a eficiência, crescimento e estabilidade); as valências sociais (importantes para a equidade, solidariedade e suporte de fatores de qualificação como os recursos humanos, a hospitalidade, a qualidade de vida); a preservação ambiental (a boa gestão, avaliação e valorização dos recursos naturais); a decisão política (gestão participada e planeamento para um bom aproveitamento dos recursos); os fatores de suporte (aspetos base de qualificação dos lugares que estão continuadamente ao serviço tanto da população local como do visitante); fatores organizacionais (importantes para a estruturação da oferta turística, facilitadores de parcerias, cooperação e ajustamento de políticas entre os stakeholders locais); e a expressão simbólica (capacidade de transmitir uma imagem com uma identidade própria).

Apesar da consciencialização de académicos, políticos e sociedade em geral sobre esta temática, segundo Sharpley (2021), poucos progressos foram realizados no sentido de implementar o turismo sustentável na prática. As razões indicadas em diversas pesquisas apontam como problema o modelo de crescimento económico em volume que tem 
fundamentado as políticas de desenvolvimento do turismo seguidas (Sharpley, 2021; Gössling et al., 2021; Torkington et al., 2020; Higgins-Desbiolles et al., 2019; Butcher, 2021). Segundo Gössling et al. (2021), o sucesso do setor tem sido visto em termos de crescimento em volume (em números), perspetiva que tem sido questionada e que se encontra desatualizada perante as dificuldades resultantes de situações como a última crise financeira, as alterações climáticas e a recente pandemia Covid-19. Referem, ainda, que as agendas de crescimento em volume parecem ser impulsionadas por indivíduos e grandes empresas que lucram com esses modelos de crescimento. Adicionalmente, Torkington et al. (2020) referem que as aspirações competitivas dos países acabam por militar contra uma possível ação cooperativa para reduzir os danos ambientais causados pelo turismo internacional, considerando que o termo sustentabilidade é usado muitas vezes "da boca para fora", mas com pouca operacionalização.

A pandemia comumente designada de Covid-19 trouxe inúmeros impactes na sociedade, economia e na atividade turística em particular. Colocou o setor do turismo numa situação difícil, com a paragem prolongada de várias atividades, o que levou as empresas a passarem por grandes dificuldades para sobreviver. A maioria dos países tentaram combater a pandemia com confinamentos, isolamento domiciliário, quarentenas, distanciamento social, o fecho temporário de escolas e serviços não essenciais e teletrabalho, situações que levaram ao cancelamento e adiamento de diversos eventos como concertos, festivais, conferências, eventos desportivos e políticos. As restrições de viagens a nível internacional, juntamente com as restrições de circulação, afetaram as diversas atividades turísticas a nível mundial. Gössling et al. (2021) analisaram o impacte da pandemia no turismo, referindo que o resultado das restrições e bloqueios de viagens levaram a uma desaceleração significativa do turismo global com o número de voos globais a caírem em mais da metade à medida que o número de casos positivos aumentava e as proibições de viagens paralisavam um número crescente de transportadoras. Em relação ao impacte na hotelaria referem que em todos os países o número de hóspedes diminuiu significativamente, em $50 \%$ ou mais. Referem também que os países mais atingidos foram os fortemente expostos à crise, que com grande número de casos motivaram manchetes dramáticas nos jornais (Itália), e também os países que impuseram medidas drásticas para restringir o movimento da população (Grécia, Alemanha) (Gössling et al., 2021).

Os impactes da pandemia nos países que mais dependem do setor veio trazer novas reflexões acerca da necessidade da sustentabilidade do turismo se efetivar. Algumas pesquisas recentes (Gössling et al., 2021; Palacios-Florencio et al., 2021; Sharpley, 2021; Butcher, 2021) evidenciam a necessidade do turismo se desenvolver de modo sustentável como forma de recuperação e retoma da atividade no pós-pandemia. Segundo Sharpley (2021) apesar do paradigma do turismo sustentável se ter popularizado nas últimas décadas pouco tem sido feito na prática para a sua implementação, representando o contexto da pandemia uma oportunidade para a adoção de níveis sustentáveis (reduzidos) de consumo. Para Palacios-Florencio et al. (2021) o turismo sustentável pode tornar-se uma solução potencial para estimular os movimentos turísticos e ajudar o renascimento da indústria do turismo. O contexto de crise de saúde causada pela Covid-19 pode ser aproveitado como impulso para aumentar uma atitude favorável em relação ao desenvolvimento do turismo 
sustentável entendendo o termo não só no sentido ecológico, mas no sentido de saudável (Palacios-Florencio et al., 2021). Segundo os autores, o alcance desta atitude permitirá um aumento da consciência do turista, traduzido na sua perceção sobre o impacte positivo e a satisfação vivenciada com o consumo deste tipo de turismo. Para Gössling et al. (2021) a magnitude da crise provocada pela pandemia Covid-19 contém mensagens importantes para o sistema de turismo no sentido da necessidade urgente de não se retornar aos negócios normais quando a crise passar e de aproveitar a oportunidade para se reconsiderar uma transformação do sistema de turismo global mais alinhada com os ODS.

Sharpley (2021) sugere que, perante a insustentabilidade do crescimento contínuo, a solução vai passar no futuro pela adoção de níveis sustentáveis (reduzidos) de consumo turístico. Refere, também, que a limitação do consumo não será um cenário fácil de implementar mesmo entre a geração pós-milenar supostamente ambientalmente consciente e que o caminho para a produção e consumo sustentável do turismo passará por uma regulamentação eficaz. No mesmo sentido, Higgins-Desbiolles et al. (2019) advogam o decrescimento justo e sustentável como uma filosofia de desenvolvimento para o turismo. $O$ crescimento económico no turismo é necessário, embora longe de ser condição suficiente para enfrentar os diversos problemas que advêm dos excessos da atividade. A este respeito, Butcher (2021) considera que não existe suficiente discussão ou evidência para que se possa entender que o decrescimento seja a solução mais adequada para o futuro da atividade.

A definição de estratégias para o desenvolvimento sustentável de destinos turísticos não parece ser um processo consensual de qualquer forma, é um processo que precisa de ser pensado e planeado. A ausência de planeamento traz riscos evidentes para o desenvolvimento do turismo, podendo levar a uma série de impactes económicos, sociais e ambientais negativos (Williams, 2003).

\section{A sustentabilidade e as estratégias nacionais para o turismo em Portugal}

A consciencialização geral acerca da importância da sustentabilidade do turismo tem levado a que os países incorporem estes aspetos nas suas políticas e planos nacionais de desenvolvimento da atividade. Normalmente, o planeamento do turismo a nível nacional representa em um país o nível mais alto de políticas para desenvolver este setor. Os planos e políticas nacionais definem as principais orientações do desenvolvimento do turismo e são as diretrizes para a elaboração de planos regionais e locais e a definição das políticas nos níveis inferiores da organização administrativa. De acordo com Williams (2003), o planeamento do turismo ao nível nacional busca definir as metas primárias para o desenvolvimento do turismo e identificar políticas e estratégias amplas para sua implementação. De acordo com este autor, os planos para o turismo geralmente refletem, num primeiro momento, preocupações com questões económicas (contribuição para o PIB, balança de pagamentos, emprego), mas, podem também pretender o desenvolvimento das regiões, proteção ambiental, marketing, entre outros (Williams, 2003).

Em Portugal, o turismo é considerado um setor estratégico de desenvolvimento económico pela sua capacidade de geração de riqueza, contribuindo para o PIB, para a criação de emprego, para a balança de pagamentos, e consequentemente para a competitividade do país. Portanto, devido a esta importância, é possível encontrar algumas 
estratégias nacionais para o desenvolvimento do setor do turismo com um forte compromisso do governo e dos stakeholders do turismo (ex.: Confederação do Turismo de Portugal, Associação da Hotelaria, Restauração e Similares de Portugal, Entidades Regionais de Turismo, CCDRs, autarquias locais).

Apesar dessa prioridade recente, o país demorou a definir uma grande política de turismo de longo prazo e a produzir algum instrumento de planeamento. Moreira (2018) refere que em Portugal o planeamento turístico era inexistente até aos anos 1980, altura em que foi publicado o primeiro Plano Nacional de Turismo, um plano de médio prazo publicado em 1986, em vigor até 1989, e que representou uma mudança nas políticas de turismo em Portugal.

As referências à sustentabilidade fizeram-se sentir mais tarde sobretudo nas grandes estratégias das últimas décadas. Entre 2006 e 2015, o Plano Estratégico Nacional do Turismo (PENT) foi a grande referência e orientação estratégica para o desenvolvimento do setor do turismo. A primeira versão do PENT foi aprovada pela Resolução do Conselho de Ministros $n^{\circ}$. 53/2007, de 4 de abril, e foi desenvolvido para o horizonte temporal 2006-2015 (Turismo de Portugal, 2013). Apresentando as linhas para o desenvolvimento estratégico do turismo, o PENT estruturou-se em 5 eixos (Turismo de Portugal, 2007): Território, Destinos e Produtos; Marcas e mercados; Qualificação de Recursos; Distribuição e Comercialização; Inovação e Conhecimento; e a sua concretização requereu a implementação de 11 projetos, em diversos níveis e englobando múltiplas entidades. Os eixos e os projetos apresentavam um foco muito empresarial e quantitativo, pretendendo sobretudo o fortalecimento da oferta com base no desenvolvimento e consolidação de dez produtos estratégicos (Sol e Mar, Touring Cultural e Paisagístico, City Break, Turismo de Negócios, Turismo de Natureza, Turismo Náutico, Saúde e Bem-estar, Golfe, Resorts Integrados e Turismo Residencial, e Gastronomia e Vinhos (Turismo de Portugal, 2007)). Esta versão do plano apresentava sobretudo objetivos de natureza quantitativa assentes no crescimento do número de turistas e receitas, nomeadamente, o crescimento sustentado acima da média europeia, traduzido na seguinte meta: "crescimento anual do número de turistas internacionais acima dos $5 \%$ e das receitas acima dos 9\%" (Turismo de Portugal, 2007: 47).

Em 2013 o PENT foi objeto de revisão (Resolução do Conselho de Ministros 24/2013 de 16 de abril) devido à necessidade de se adequar às mudanças estratégicas do programa do XIX Governo, devido à instabilidade dos mercados financeiros e ao moderado crescimento económico das principais economias europeias emissoras de turismo para Portugal e, ainda porque a realidade mostrara que a definição dos objetivos não havia sido realista, pois os resultados haviam ficado muito aquém das expectativas (Turismo de Portugal, 2013). Assim, com um enfoque quantitativo, foram definidos objetivos mais prudentes que passaram por aumentar as taxas de ocupação e as receitas num contexto de crescimento moderado da oferta (Turismo de Portugal, 2013). A estratégia 2013-2015 continuou a assentar nos 10 produtos definidos no PENT de forma a reforçar a importância da estabilidade da oferta na perceção externa do destino (Turismo de Portugal, 2013). Para atingir os objetivos, foram definidos 8 programas de desenvolvimento e implementados 40 projetos (Turismo de Portugal, 2013). 
Neste documento é possível encontrar uma referência explícita à pretensão da estratégia contribuir para o desenvolvimento sustentável. É referido ao nível da visão que: "Portugal deve ser um dos destinos na Europa com crescimento mais alinhado com os princípios do desenvolvimento sustentável, alavancado numa proposta de valor suportada em características distintivas e inovadoras do país" (Turismo de Portugal, 2013: 9). A estratégia afirmava-se dirigida para um desenvolvimento sustentável, explicando que procurava a sustentabilidade dos destinos, promovendo os efeitos positivos e atenuando os impactes negativos nas regiões e populações a vários níveis (Turismo de Portugal, 2013), nomeadamente: sustentabilidade do desenvolvimento (fomentando o empreendedorismo e o desenvolvimento de fileiras); sustentabilidade económica (qualificação dos recursos humanos e do produto); aposta na inovação e num modelo de gestão da sazonalidade; urbanismo (valorizando a autenticidade, pela conservação e valorização do património, e intervindo em áreas públicas e exteriores); sustentabilidade do ambiente (utilização racional dos recursos naturais e na valorização do património natural); paisagens naturais e culturais (relação entre o turista e o espaço, região e comunidades da envolvência, contribuindo para a experiência global da visita). No entanto, não são identificadas metas para este intuito e as pretensões da sustentabilidade parecem ser usadas teoricamente no plano, mas com pouca concretização prática.

Em 2015, o Turismo de Portugal lançou dois documentos estratégicos com base no horizonte temporal de 2020: Turismo 2020 - 5 Princípios para uma Ambição (1); e Turismo 2020 - Plano de Ação (2). Assim, o PENT foi revogado e substituído pelo Plano Turismo 2020, que definiu os princípios norteadores das políticas públicas de turismo 2016-2020. Este plano (1) distingue-se do anterior por visar uma ambição assente no setor privado do turismo, uma influência da filosofia dos partidos de direita que constituíram o XIX Governo constitucional. Este plano continua tal como os anteriores a ter um enfoque quantitativo neste caso apresentando-se de forma muito ambiciosa pretendendo no horizonte 2020 tornar Portugal no destino mais ágil e dinâmico da Europa criando condições para que as receitas auferidas pelo setor privado do turismo crescessem acima da média dos seus concorrentes e ser um dos dez destinos mais competitivos do mundo (Turismo de Portugal, 2015a). O plano expressava esta ambição de seis formas diferentes (Turismo de Portugal, 2015a): 1. Um destino sustentável e de qualidade; 2. Um destino de empresas competitivas; 3. Um destino empreendedor; 4. Um destino ligado ao Mundo; 5. Um destino gerido de forma eficaz; 6. Um destino que marca. Pretendia-se que os objetivos de crescimento turístico fossem suportados na sustentabilidade e na competitividade da oferta turística referidas na primeira ambição do plano. Era entendido que a qualificação e a sustentabilidade são essenciais para manter e reforçar a atratividade e notoriedade do destino turístico, reduzir a sazonalidade, dinamizar o turismo interno, sustentar o crescimento e para criar novas propostas de valor. É também referido que a sustentabilidade e a qualidade são conceitos que vão para além do cumprimento de objetivos ambientais ou urbanísticos, não estão reservados para o edificado ou para o turismo de natureza, mas, que são valores transversais ao setor do turismo e desafios próprios de todas as políticas de turismo (Turismo de Portugal, 2015a). Apesar deste entendimento, os pressupostos e as linhas de atuação definidas no plano podiam ter sido mais ambiciosas e explícitas quanto a estes aspetos pois, tal como nos planos anteriores, o objetivo central continua a ser o crescimento do turismo. 
O Turismo 2020 - Plano de Ação (2) consistiu no referencial estratégico que estabeleceu os objetivos e as prioridades de investimento na área do turismo enquadrados no Portugal 2020, o programa de fundos europeus de investimento para Portugal (Turismo de Portugal, 2015b). Este plano segue o ciclo de programação da Comunidade Europeia, visando identificar as prioridades de utilização dos fundos comunitários para o período de programação 2014-2020, estabelecendo objetivos e atribuindo os fundos estruturais e de investimento europeus como forma de reforçar a coordenação setorial e territorial. Forneceu um quadro de referência estratégico para o desenvolvimento do turismo, estabelecendo que Portugal fosse

(... ) o destino com maior crescimento turístico na Europa, suportado na sustentabilidade e na competitividade de uma oferta turística diversificada, autêntica e inovadora, consolidando o turismo como uma atividade central para o desenvolvimento económico do país e para a sua coesão territorial. (Turismo de Portugal, 2015b: 147)

Esta visão foi consubstanciada num conjunto de 5 objetivos estratégicos (Turismo de Portugal, 2015b): Atrair - Qualificação e valorização do território e dos seus recursos turísticos distintivos; Competir - Reforço da competitividade e internacionalização das empresas turísticas; Capacitar - Capacitação, Formação e, I\&D e inovação em turismo; Comunicar - Promoção e comercialização da oferta turística do país e das regiões; Cooperar - Reforço da cooperação internacional.

Neste documento a palavra sustentabilidade é frequentemente usada desde logo na visão que se pretende para Portugal e, em especial, no que diz respeito ao $1^{\circ}$ objetivo estratégico em que se pretende uma valorização do território (entendido como recurso turístico por excelência) através de um reforço da sustentabilidade dos seus componentes (Turismo de Portugal, 2015b). As prioridades de investimento iam no sentido desta qualificação e valorização do território e dos seus recursos turísticos distintivos (Turismo de Portugal, 2015b). Também entre os objetivos temáticos, 4 encontram-se associados ao crescimento sustentável (OT4-Apoiar a transição para uma economia de baixo teor de carbono; OT5-Promover a adaptação às alterações climáticas e a prevenção e gestão de riscos; OT6-Proteger o ambiente e promover a eficiência energética; OT7-Promover transportes sustentáveis e eliminar os estrangulamentos nas principais redes de infraestruturas distintivos) (Turismo de Portugal, 2015b). Também neste plano a sustentabilidade é apoiada no crescimento do turismo.

Em 2017 foi lançada a Estratégia Turismo 2027 (ET27) a qual foi aprovada pela Resolução do Conselho de Ministros $n^{\circ} .134 / 2017$, de 27 de setembro, pretendendo-se que seja na próxima década, a referência estratégica para o Turismo em Portugal e o enquadramento a seguir para o próximo quadro comunitário de apoio 2021-2027. A ET27 define como visão: "afirmar o turismo como hub para o desenvolvimento económico, social e ambiental em todo o território, posicionando Portugal como um dos destinos turísticos mais competitivos e sustentáveis do mundo" (Turismo de Portugal, 2017: 6). A sua operacionalização e materialização passa pela implementação de projetos, com base nas linhas de ação dos seus 5 eixos ou objetivos estratégicos (Turismo de Portugal, 2017): Valorizar o território e as 
comunidades; impulsionar a economia; potenciar conhecimento; gerar redes e conectividade; e projetar Portugal.

Mais do que outras estratégias anteriores a ET27 é de facto aquela que mais evoca e enfoca a questão da sustentabilidade do turismo afirmando-se explicitamente comprometida com metas de sustentabilidade económica, social e ambiental (Turismo de Portugal, 2017):

- Metas de sustentabilidade económica:

- Aumentar a procura em todo o território: 80 milhões de dormidas;

- Crescer em valor: 26 mil milhões de euros em receitas;

- Metas de sustentabilidade social:

- Alargar a atividade turística a todo o ano, atingindo em 2027 o índice de sazonalidade mais baixo de sempre;

- Duplicar o nível de habilitações do ensino secundário e pós-secundário no turismo (de 30\% para 60\%);

- Assegurar que o turismo gera um impacte positivo nas populações residentes;

- Metas de sustentabilidade ambiental:

- Assegurar que mais de $90 \%$ das empresas do turismo adotam medidas de utilização eficiente de energia e da água e desenvolvem ações de gestão ambiental dos resíduos.

Para além das metas, as referências à sustentabilidade aparecem ao longo do documento na visão, nos objetivos estratégicos e nos desafios que a ET27 assume a dez anos. De facto, a ET27 é o primeiro documento que assume a sustentabilidade de acordo com a definição da UNEP/WTO compatibilizando as três dimensões que lhe estão inerentes e englobando em cada uma um conjunto de metas concretas e objetivas a cumprir.

\section{O efeito da pandemia na estratégia nacional para o turismo}

A pandemia Covid-19 veio provocar a nível nacional diversos impactes no turismo, na economia e na sociedade em geral. Em Portugal foram aplicadas a maioria das restrições de circulação e de viagens aplicadas noutros países que tiveram fortes consequências na atividade turística nacional. Os confinamentos, as quarentenas e o distanciamento social aliados ao fecho temporário de escolas e serviços não essenciais e ao teletrabalho levaram ao cancelamento de diversos eventos e forçaram a paragem prolongada de várias atividades turísticas.

A situação presente da economia do turismo, em Portugal, contrasta com o crescimento alcançado dos últimos anos nos diversos indicadores (Tabela 1). 
Tabela 1 - Evolução dos principais indicadores da procura turística em Portugal

\begin{tabular}{|l|r|r|r|r|r|r|}
\cline { 2 - 7 } \multicolumn{1}{c|}{} & \multicolumn{1}{c|}{2014} & \multicolumn{1}{c|}{2017} & \multicolumn{1}{c|}{$\mathbf{2 0 1 8}$} & \multicolumn{1}{c|}{2019} & $\begin{array}{c}\text { 2020 } \\
\text { (prelim.) }\end{array}$ & $\begin{array}{c}\text { 2021 } \\
\left(\mathbf{1 .} .^{\circ} \text { sem. }\right)\end{array}$ \\
\hline Chegadas & 9277000 & 21200000 & 22800000 & 24600000 & 5971000 & \\
\hline $\begin{array}{l}\text { Receitas (milhões } \\
\text { de } € \text { ) }\end{array}$ & 13808 & 15550 & 17053 & 18291 & 7753 & \\
\hline Hóspedes & 17301622 & 23953765 & 25249904 & 27142416 & 10515778 & 3585512 \\
\hline Dormidas & 55912865 & 65385210 & 67662103 & 70158964 & 25968100 & 8170944 \\
\hline
\end{tabular}

Fonte: UNWTO (2021), Pordata (2021) e Turismo de Portugal (2021a)

Segundo o Turismo de Portugal (2021a), na sequência das medidas restritivas adotadas durante o ano de 2020, verificou-se uma contração sem precedentes na atividade turística. Os mais recentes dados mostram que o setor do alojamento turístico registou cerca de 10,5 milhões de hóspedes e quase 26 milhões de dormidas em 2020, o que correspondeu a decréscimos de $61,3 \%$ dos hóspedes e de $62,9 \%$ das dormidas face a 2019 , notando-se uma maior diminuição nas dormidas por parte dos não residentes (Turismo de Portugal, 2021a).

No primeiro semestre de 2021 (Tabela 2), apesar da tendência de crescimento dos indicadores, não foram atingidos os valores do primeiro semestre de 2020. Os hóspedes registados foram menos 751,6 milhares que no ano anterior e as dormidas menos 2205,7 milhares.

Tabela 2 - Hóspedes, dormidas e percentagem de estabelecimentos encerrados nos alojamentos turísticos (2021)

\begin{tabular}{|l|r|r|r|r|r|r|}
\cline { 2 - 6 } \multicolumn{1}{l|}{} & \multicolumn{1}{c|}{ Janeiro } & Fevereiro & \multicolumn{1}{c|}{ Março } & \multicolumn{1}{c|}{ Abril } & \multicolumn{1}{c|}{ Maio } & Junho \\
\hline Hóspedes & 300770 & 205836 & 279660 & 451355 & 980315 & 1367576 \\
\hline Dormidas & 697865 & 468372 & 625508 & 932253 & 2043531 & 3403415 \\
\hline \% Estabel. Encerrados & $57,0 \%$ & $63,9 \%$ & $60,4 \%$ & $47,6 \%$ & $37,2 \%$ & $25,3 \%$ \\
\hline
\end{tabular}

Fonte: INE (2021a)

Isto deveu-se ao facto de a procura no primeiro trimestre de 2020 pouco ter sido afetada pela pandemia, enquanto que o ano de 2021 foi um dos períodos com maiores restrições de viagens. De destacar ainda a resposta dos estabelecimentos de alojamento a estas restrições, que levou ao encerramento de $63,9 \%$ das unidades, em fevereiro de 2021 , valor que tem vindo a diminuir ao longo do ano.

O Gráfico 1 mostra a evolução das dormidas nos estabelecimentos de alojamento turístico desde 2018. Nunca antes se tinha registado uma quebra semelhante à que ocorreu a partir de março de 2020. Nota-se uma ligeira recuperação na época do Verão de 2020, mas 
seguida de nova quebra a partir do final de agosto. Apesar das dormidas entre abril e junho de 2021 serem superiores às do período homólogo de 2020, no primeiro semestre do ano houve uma diminuição de $21,3 \%$ das dormidas totais (aumento de $23,7 \%$ nas dormidas dos residentes e diminuição de $50,8 \%$ nas dos não residentes). Comparando com o mesmo período de 2019, as dormidas registaram uma diminuição de $73,4 \%$ (42,3\% nos residentes e $85,9 \%$ nos não residentes).

Gráfico 1 - Evolução mensal das dormidas em estabelecimentos turísticos (2018-2021)

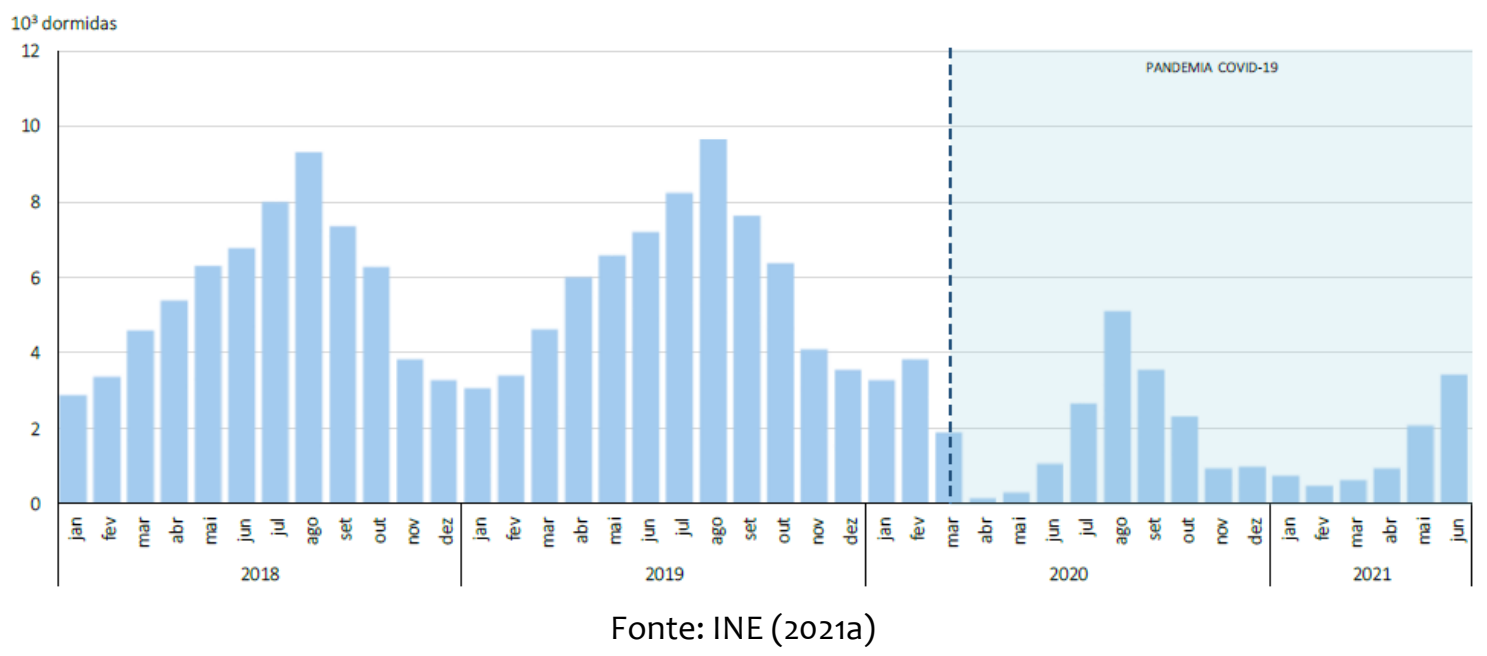

Quanto às viagens turísticas dos residentes, os dados do INE (2021b) relativos ao primeiro trimestre de 2021 revelam que continuou a verificar-se uma redução significativa. As viagens no território nacional (cerca de $97 \%$ das deslocações registadas) decresceram $53,3 \%$, mas o decréscimo ainda foi mais acentuado nas viagens com destino ao estrangeiro, que diminuíram 89,5\%.

De acordo com o Turismo de Portugal (2021b), a recuperação da economia pós Covid-19 deverá ter como prioridade aspetos ambientais e sociais, no sentido de impor uma transição rápida para modelos de desenvolvimento sustentáveis. Segundo o Plano Turismo +Sustentável 20-23, "a sustentabilidade no Turismo é um objetivo e um caminho que deve ter em conta as necessidades dos visitantes, do setor e das comunidades, bem como os seus impactes ambientais, económicos e sociais no presente e no futuro" (Turismo de Portugal, 2021b: 5).

Para Daniel e Fernandes (2020: 11), "há claramente que rever formatos de funcionamento e formas de operacionalizar os produtos turísticos, promovendo, de forma colaborativa a segurança, a confiança e o bem-estar dos turistas, sem comprometer a satisfação da experiência turística". No mesmo sentido, a ET27 já identificava como objetivo para o país tornar-se um destino sustentável, "onde o desenvolvimento turístico assenta na conservação e na valorização do património natural e cultural identitário e contribui para a permanência e a melhoria da qualidade de vida da comunidade local" (Turismo de Portugal, 2017: 40).

O Turismo de Portugal (2021b) encara a recuperação do setor após a pandemia Covid-19 com base na sustentabilidade como uma forma de assegurar maior resiliência perante outras futuras crises, permitindo uma retoma da atividade com maior qualidade e segurança ao nível 
económico, social e ambiental. Portanto, a pandemia deve ser encarada como uma oportunidade de planear o futuro das atividades turísticas de acordo com os fundamentos da sustentabilidade.

A necessidade de recuperação do setor e da atividade em Portugal está a ser enquadrada pela publicação, em junho de 2021, do Plano Turismo +Sustentável 20-23. Este plano representa o referencial estratégico para os próximos três anos, encontrando-se alinhado com os objetivos da Estratégia Turismo 2027 e apresentando como propósito "Posicionar Portugal como um dos destinos turísticos do mundo mais sustentáveis, competitivos e seguros, através do planeamento e desenvolvimento sustentável das atividades turísticas, do ponto de vista económico, social e ambiental, em todo o território" (Turismo de Portugal, 2021b: 3).

O Turismo de Portugal (2021b) enquadra o plano num conjunto de estratégias globais (ex.: Objetivos de Desenvolvimento Sustentável), europeias (ex.: Pacto Ecológico Europeu) e nacionais (ex.: Plano de Ação para a Economia Circular, Estratégia Turismo 2027, Plano de Recuperação e Resiliência), em que o turismo é visto como uma atividade que pode contribuir para o desenvolvimento sustentável.

Os Plano Turismo +Sustentável 20-23 rege-se por cinco princípios orientadores que são os seguintes (Turismo de Portugal, 2021b):

1. Contribuir para alcançar as metas da Estratégia Turismo 2027;

2. Reforçar o papel do turismo nos 17 Objetivos de Desenvolvimento Sustentável das Nações Unidas;

3. Promover a transição energética e a agenda para a economia circular das empresas turísticas;

4. Envolver os stakeholders do setor num compromisso conjunto de transformação da oferta e sustentabilidade do destino;

5. Estimular uma mudança de atitude em toda a cadeia de valor.

Dentro dos quatro eixos de atuação identificados (ESTRUTURAR uma oferta cada vez mais sustentável, QUALIFICAR os agentes do setor, PROMOVER Portugal como um destino sustentável, e MONITORIZAR as métricas de sustentabilidade no setor), o plano apresenta um programa de 119 ações a desenvolver em articulação com um vasto conjunto de parceiros institucionais identificados, no sentido de responder da forma mais eficaz possível aos desafios atuais do setor. A sua gestão e monitorização ao longo dos três anos previstos levarão à reavaliação do Plano para assegurar a sua "continuidade a partir de 2024, como uma segunda fase do desafio de tornar Portugal um destino turístico cada vez mais sustentável" (Turismo de Portugal, 2021: 68).

No sentido de dar resposta às dificuldades que o setor do turismo atravessa desde o início da situação de pandemia em Portugal, nomeadamente as referentes à grande redução da procura e ao encerramento de diversas atividades, foram vários os instrumentos utilizados pelo Governo. Desde as iniciativas mais imediatas, como a concessão de subsídios ou as moratórias de créditos, passando pelos apoios ao lay-off, até ao Plano de Recuperação e Resiliência, o Plano Turismo +Sustentável 20-23 surge como um instrumento importante para o setor do turismo. Este Plano procura provocar um aceleramento na implementação dos 
princípios da sustentabilidade no desenvolvimento da atividade turística, algo que já seria previsível de vir a suceder de acordo com o planeado na ET27 e dadas as estratégias globais de desenvolvimento sustentável em que Portugal se enquadra. Pode então dizer-se que a pandemia aumentou a preocupação com o desenvolvimento sustentável, trazendo uma oportunidade de repensar e planear o futuro e, portanto, de reflexão e renovação das atividades turísticas com base nos referidos princípios para este tipo de desenvolvimento.

\section{Discussão e conclusões}

O crescimento acentuado do turismo nas últimas décadas tem revelado uma crescente preocupação com o desenvolvimento sustentável da atividade turística. Apesar da ambiguidade do conceito, a sustentabilidade tem sido associada à compatibilização de aspetos ambientais, económicos e socioculturais de desenvolvimento do turismo com o intuito de se alcançar um equilíbrio entre o turismo, o ambiente, a economia e a sociedade. Apesar da consciencialização geral do tema, a sua implementação prática tem tido poucos progressos estando o problema associado ao modelo de desenvolvimento da atividade fundamentado sobretudo em objetivos de crescimento turístico, os quais ficam totalmente comprometidos perante situações como a última crise financeira, as alterações climáticas e as pandemias.

Em Portugal as estratégias nacionais de desenvolvimento do turismo nem sempre refletiram esta preocupação, que só se manifestou sobretudo nos planos da última década. A primeira versão do PENT de 2007 assentava sobretudo num objetivo de natureza quantitativo assente no crescimento do número de turistas e das receitas. Os eixos e projetos apresentavam um foco muito empresarial e quantitativo, pretendendo sobretudo o fortalecimento da oferta com base no desenvolvimento e consolidação de dez produtos estratégicos. A realidade revelou que os objetivos foram, por diversas razões (lembremos o contexto da crise financeira, entre outras), demasiado ambiciosos e os resultados ficaram muito aquém das expetativas, levando à sua revisão e definição de forma mais prudente, mas ainda com enfoque quantitativo e baseado num crescimento moderado da oferta. De qualquer forma, é na revisão de 2013 do plano que se pode encontrar uma referência explícita da estratégia pretender um crescimento mais alinhado com os princípios do desenvolvimento sustentável.

Quanto aos documentos estratégicos de 2015, tal como nos planos anteriores, o objetivo central continua a ser o crescimento do turismo apesar de a sustentabilidade ser referida como essencial para manter e reforçar a atratividade e notoriedade do destino turístico. $\mathrm{O}$ turismo é neste plano entendido como uma atividade central para o desenvolvimento económico do país.

De entre as grandes estratégias deve destacar-se a Estratégia Turismo 2027 (ET27) de 2017 que constitui a referência estratégica atual para o Turismo em Portugal. A ET27 define o turismo como hub para o desenvolvimento económico, social e ambiental em todo o território, pretendendo posicionar Portugal como um dos destinos turísticos mais competitivos e sustentáveis. É o primeiro documento que assume a sustentabilidade de acordo com a definição da UNEP/WTO, compatibilizando as três dimensões que lhe estão inerentes, enunciando e comprometendo-se com um conjunto de metas de sustentabilidade económica, social e ambiental. Mais do que os anteriores planos que destacavam a nível dos 
seus objetivos a prioridade do crescimento turístico e, sobretudo, a vertente económica, nesta estratégia essas metas continuam a fazer parte dos objetivos, mas são acompanhadas e combinadas de metas referentes às vertentes sociais e ambientais que estão subjacentes à noção de sustentabilidade.

A pandemia Covid-19 que assola o país e o mundo desde o ano passado veio colocar as empresas turísticas em grandes dificuldades dada a paragem das suas atividades. As diversas restrições de circulação e bloqueios de viagens por todo o mundo levaram a uma desaceleração significativa do turismo a nível global. Os impactes da pandemia Covid-19 na atividade turística vieram trazer novas reflexões acerca do modelo de crescimento do turismo e da necessidade da sustentabilidade do turismo se concretizar efetivamente. Algumas pesquisas recentes (Gössling et al., 2021; Palacios-Florencio et al., 2021, Sharpley, 2021; Butcher, 2021) indicam a necessidade do turismo se desenvolver de acordo com os princípios de sustentabilidade como forma de recuperação e retoma da atividade no póspandemia.

A nível nacional, o Turismo de Portugal (2021b) encara a recuperação do setor com base na sustentabilidade como forma de resistência perante futuras crises e para uma retoma da atividade com maior qualidade e segurança ao nível económico, social e ambiental. Nesse sentido publicou, em junho de 2021 o Plano Turismo +Sustentável 20-23, que vem guiar a retoma e recuperação do setor e representa o referencial estratégico para os próximos três anos, encontrando-se alinhado com os objetivos da ET27 e enquadrando-se num conjunto de estratégias globais, europeias e nacionais. O principal efeito da pandemia na estratégia nacional foi levar a um aceleramento na implementação de práticas sustentáveis no desenvolvimento da atividade, algo que já seria previsível de vir a suceder de acordo com o planeado na ET27 e dadas as estratégias globais de desenvolvimento sustentável em que Portugal se enquadra.

A pandemia veio tornar mais evidente a necessidade de ponderar mudanças nos modelos de negócio e mudança de comportamentos de consumo para níveis mais sustentáveis. A paragem nas atividades turísticas derivada da pandemia apresenta-se como um momento de oportunidade para repensar e ponderar. A recuperação da economia parece passar por uma transição para modelos de negócio e desenvolvimento mais sustentáveis, tanto pela maior consciência e preocupação com a segurança sanitária, mas também com as questões da mudança climática, entre outras. Neste contexto as instituições públicas têm um papel decisivo em desenvolver políticas voltadas para a promoção e incentivo do turismo sustentável. No entanto, os desafios impostos pela pandemia implicam que a sustentabilidade não passe só de uma ambição patente em planos ou de uma operação de marketing, mas que se assuma de facto como uma atitude que se reflita em mudanças de comportamentos num compromisso conjunto dos diversos agentes do setor.

Apesar de ser identificado como um dos ativos qualificadores da oferta na ET27 (Turismo de Portugal, 2017), os eventos de negócios (entre outras formas de turismo de negócios) poderão não voltar a recuperar a importância que tinham para destinos como Lisboa, uma vez que as tecnologias de teletrabalho e videoconferência provaram permitir assegurar a realização de alguns destes eventos sem deslocações e com custos mais reduzidos. 
Dado que muitos dos efeitos da pandemia se estão e vão continuar a sentir importa que se continue a investigar e refletir sobre as formas de recuperar o setor. Desta forma, sugerese que em estudos futuros seja analisada a monitorização da implementação da estratégia nacional, acompanhando a evolução dos indicadores previstos no plano por forma a perceber se a sustentabilidade se está, de facto, a efetivar. Sugere-se, também, o estudo dos fatores que motivam os turistas a preferirem destinos turísticos sustentáveis e o nível de disponibilidade para adaptar comportamentos de consumo a níveis sustentáveis ou mais reduzidos. Seria ainda relevante estudar os níveis de produção e consumo turísticos sustentáveis, para perceber quais os padrões que podem ser considerados sustentáveis. Face às alterações na procura decorrentes da pandemia, mostra-se também fundamental acompanhar a evolução do papel do turismo doméstico na recuperação do setor.

\section{Referências}

Almeida, I. \& Abranja, N. (2009). Turismo e sustentabilidade. Cogitur: Journal of Tourism Studies, 2, 1531

Butcher, J. (2021). Covid-19, tourism and the advocacy of degrowth. Tourism Recreation Research (online version). https://doi.org/10.1080/02508281.2021.1953306

Daniel, A. \& Fernandes, G. (2020). A Importância Económica do Turismo em Portugal e no Mundo e o Impacto Covid. XIX Encuentro Internacional AECA. Instituto Politécnico da Guarda.

Gössling, S.; Scott, D. \& Hall, C. M. (2021). Pandemics, tourism and global change: A rapid assessment of COVID-19. Journal of Sustainable Tourism, 29(1), 1-20. https://doi.org/10.1080/09669582.2020.1758708

Higgins-Desbiolles, F.; Carnicelli, S.; Krolikowski, C.; Wijesinghe, G. \& Boluk, K. (2019) Degrowing tourism: Rethinking tourism. Journal of Sustainable Tourism, 27(12), 1926-1944. https://doi.org/10.1080/09669582.2019.1601732

Holden, A. (2008). Environment and Tourism (Second Edition). Routledge.

INE (Insituto Nacional de Estatística) (2021a). Destaques: Atividade Turística - Estimativa Rápida: Junho de 2021. Portal do INE.

INE (Insituto Nacional de Estatística) (2021b). Destaques: Procura Turística dos Residentes. Portal do INE.

Moreira, C. (2018). Portugal as a tourism destination: Paths and trends. Méditerranée, 130. https://doi.org/10.4000/mediterranee.10402

Palacios-Florencio, B.; Santos-Roldán, L.; Berbel-Pineda, J.M. \& Castillo-Canalejo, A.M. (2021). Sustainable tourism as a driving force of the tourism industry in a post-Covid-19 scenario. Social Indicators Research, 158, 991-1011. https://doi.org/10.1007/s11205-021-02735-2

Pordata (2021). Turismo. Pordata, base de dados Portugal contemporâneo.

Santos, N.P. (2014). Turismo, gestão e território. Caderno Virtual de Turismo, Edição especial: Hospitalidade e políticas públicas em turismo, 14, 66-86.

Sharpley, R. (2021). On the need for sustainable tourism consumption. Tourist Studies, 21 (1), 96-107. https://doi.org/10.1177/1468797620986087

Torkington, K., Stanford, D. \& Guiver, J. (2020). Discourse(s) of growth and sustainability in national tourism policy documents. Journal of Sustainable Tourism, 28(7), 1041-1062. https://doi.org/10.1080/09669582.2020.1720695

Turismo de Portugal (2007). Plano Estratégico Nacional do Turismo: Para o Desenvolvimento do Turismo em Portugal. Turismo de Portugal.

Turismo de Portugal (2013). Plano Estratégico Nacional do Turismo: Revisão e Objetivos 2013-2015. Turismo de Portugal. 
Turismo de Portugal (2015a). Turismo 2020: Cinco princípios para uma ambição. Turismo de Portugal. Turismo de Portugal (2015b). Turismo 2020: Plano de Ação para o Desenvolvimento do Turismo em Portugal. Turismo de Portugal.

Turismo de Portugal (2017). Estratégia Turismo 2027: Liderar o Turismo do Futuro. Turismo de Portugal. Turismo de Portugal (2021a). TravelBI. TravelBI by Turismo de Portugal.

Turismo de Portugal (2021b). PLANO TURISMO +SUSTENTÁVEL 20-23. Turismo de Portugal.

United Nations (1987). Our common future. Report of the World Commission on Environment and Development. United Nations.

United Nations (1992). Agenda 21. United Nations.

United Nations (2020). The 17 Goals. United Nations: Department of Economic and Social Affairs.

United Nations Environment Programme/World Tourism Organization (2005). Making tourism more sustainable: A guide for policy makers. UNEP/WTO.

UNWTO (2021). UNWTO World Tourism Barometer (English version). UNWTO eLibrary.

Williams, S. (2003). Tourism geography. Routledge.

SANDRA BAILOA é doutorada em Gestão pela Universidade de Évora. É docente do Instituto Politécnico de Beja desde 1997, com a categoria de Professora Adjunta. Nos últimos anos tem lecionado as unidades curriculares de Microeconomia, Macroeconomia, Gestão Estratégica e Economia do Turismo, entre outras. As suas áreas de interesse e investigação são a Gestão estratégica, Economia, Turismo e Capital intelectual. Endereço institucional: Departamento de Ciências Empresariais, ESTIG - Escola Superior de Tecnologia e Gestão de Beja, Instituto Politécnico de Beja, R. Pedro Soares, Campus do Instituto Politécnico de Beja, 7800-295 Beja, Portugal.

PEDRO CRAVO é pós-graduado em Gestão e Desenvolvimento em Turismo, pela Faculdade de Economia da Universidade do Algarve, e em Desenvolvimento Comunitário e Empreendedorismo, pelo Instituto Politécnico de Beja. É docente do Instituto Politécnico de Beja desde 1996, com a categoria de Assistente. Nos últimos anos tem lecionado as unidades curriculares de Empreendedorismo, Atividades de Intermediação Turística e Novas Tecnologias em Turismo, entre outras. As suas áreas de interesse e investigação são o Desenvolvimento Turístico, o Empreendedorismo, a Inovação e as Novas Tecnologias. Endereço institucional: Departamento de Ciências Empresariais, ESTIG - Escola Superior de Tecnologia e Gestão de Beja, Instituto Politécnico de Beja, R. Pedro Soares, Campus do Instituto Politécnico de Beja, 7800-295 Beja, Portugal.

Submetido em 1 de fevereiro 2021

Aceite em 8 de outubro 2021 